\title{
Medição de desempenho em cadeias de suprimentos: um estudo na indústria automobilística
}

\author{
Performance measurement in supply chains: a study in the \\ automotive industry
}

\author{
Mário Sacomano Neto ${ }^{1}$ \\ Silvio Roberto Ignácio Pires ${ }^{1}$
}

\begin{abstract}
Resumo: Muito da base conceitual sobre medição de desempenho nas empresas industriais foi construído sob a perspectiva interna, ou seja, empresas tratadas individualmente. Com o advento e expansão do conceito de gestão da cadeia de suprimentos, cresceu a demanda por uma revisão do conhecimento e dos sistemas de medição à luz da cadeia como um todo. Por sua vez, a introdução dos novos arranjos produtivos na indústria automobilística, como os condomínios industriais, estimulou o desenvolvimento de novos padrões de relacionamento nas cadeias de suprimentos, trazendo consigo novas formas de se conduzir a gestão de desempenho entre empresas. Nesse contexto, a pesquisa realizada teve como propósito principal identificar a ocorrência e analisar as principais características da medição de desempenho em uma representativa cadeia de suprimentos da indústria automobilística brasileira, a qual utiliza um sistema de montagem do tipo condomínio industrial. A pesquisa teve um caráter exploratório, descritivo, e a coleta de dados foi realizada principalmente por meio de entrevistas (seguindo um questionário semiestruturado) com executivos envolvidos com o tema de estudo nas referidas empresas. Como principal resultado, a pesquisa não identificou a ocorrência de um sistema único de medição de desempenho da cadeia de suprimentos estudada. O constatado é que o sistema de medição de desempenho interno da montadora desdobra-se a montante e a jusante, com claras implicações nos sistemas de medição de desempenho dos quatro fornecedores e da concessionária estudados. A partir dos indicadores de desempenho das empresas, pode-se constatar que as medidas a montante são fortemente direcionadas para os aspectos operacionais relacionados à qualidade, produção e desempenho das entregas e as medidas a jusante apresentam um caráter mais estratégico e mercadológico. Também, tem-se que a medição de desempenho na cadeia tende a ser mais intensa nos relacionamentos mais colaborativos.
\end{abstract}

Palavras-chave: Medição de desempenho. Gestão da cadeia de suprimentos. Indústria automobilística.

\begin{abstract}
Much of the literature on performance measurement in industrial companies is based on an internal perspective, i.e., companies are investigated individually. With the emergence of the supply chain management concept, the demand for a review of knowledge and performance measurement systems has increased considering the supply chain as a whole. Thus, the introduction of new productive configurations, such as the industrial condominium, has stimulated the development of new standards of relationship in supply chains introducing new ways to conduct performance management. Therefore, the main objective of the present study was to identify the occurrence and to analyze the key characteristics of performance measurement in a representative supply chain of the Brazilian automotive industry that has an industrial condominium configuration. This study was exploratory in nature, and the data were collected through interviews conducted with executives involved with this topic in these companies using a semi-structured questionnaire. As main result, the occurrence of a single supply chain performance measurement system was not identified in the supply chain studied. In fact, the automaker internal performance measurement system unfolds upstream and downstream affecting the performance measurement systems of the four suppliers and the car dealer studied. Analyzing the performance indicators of these companies, it can be said that the upstream measures are connected to the operational aspects related to quality, production, and delivery performance, while the downstream measures are more strategic and related to marketing. Furthermore, it was also found that the supply chain performance measurement tends to be more intense in collaborative relationships.
\end{abstract}

Keywords: Performance measurement. Supply chain management. Automotive industry.

\footnotetext{
${ }^{1}$ Programa de Pós-graduação em Administração - PPGA, Faculdade de Gestão e Negócios, Universidade Metodista de Piracicaba - UNIMEP, Rod. do Açúcar, Km 156, SP-308, CEP 13423-170, Piracicaba, SP, Brasil, e-mail: msacomano@unimep.br; sripires@unimep.br
}

Recebido em 15/2/2010 — Aceito em 12/9/2012

Suporte financeiro: CNPq. 


\section{Introdução}

As recentes transformações e grande crescimento do setor automobilístico brasileiro abrem um vasto campo de pesquisa envolvendo a gestão da cadeia de suprimentos e as medidas de desempenho. $\mathrm{O}$ grande número de fusões, aquisições, coprodução, condomínios, alianças estratégicas, contratos de longo prazo e joint ventures mostram o caráter dinâmico e complexo da estrutura competitiva e cooperativa do setor. Essa mudança do padrão de relacionamento entre montadoras, fornecedores e concessionárias (dealers) tende a criar uma demanda pela medição de desempenho além dos limites físicos tradicionais das empresas. Isso também tende a ser reforçado pelo fato de que a racionalização interna das empresas chegou a um estágio de saturação após a implantação de vários sistemas de melhorias de qualidade e produtividade.

Nos últimos quinze anos, diversos novos arranjos produtivos foram implantados no setor automobilístico no Brasil, entre eles o consórcio modular e os condomínios industriais. Esses novos arranjos são caracterizados por um grau elevado de outsourcing, contratos de longo prazo, acordos integrativos, coprodução de componentes, troca de ativos específicos, transferência de informações e suporte aos fornecedores. Eles também modificam o relacionamento das montadoras com os fornecedores de autopeças (HELPER, 1991; LAMMING, 1993; LAMBERT; COOPER; PAGH, 1998; FLEURY, 1999; CROXTON et al., 2001; ALVES FILHO et al., 2004; PIRES; SACOMANO NETO, 2008; ALÁEZ-ALLER; LONGÁS-GARCÍA, 2010)

Existem duas consequências básicas dessas mudanças para o setor de autopeças: (1) um aumento significativo das exigências das montadoras quanto à qualidade, entregas just-in-time, global sourcing, follow sourcing, desenvolvimento de produtos, fornecimento de funções completas (sistemas, subsistemas ou módulos), co-design, capacitação financeira e tecnológica; (2) maior concentração dos fornecedores de autopeças nas mãos de grandes grupos internacionais e uma desnacionalização do setor (CARVALHO et al., 2000). Essas exigências de desempenho com os fornecedores também são verificadas em elos a jusante das empresas, como clientes e distribuidores, (CHIA et al., 2009; HILSDORF; ROTONDARO; PIRES, 2009; OU et al., 2010). Consequentemente, a consolidação da base de fornecedores e o repasse (outsourcing) de processos internos têm levado muitas montadoras a estabelecer novos mecanismos de medição de desempenho a jusante (concessionárias) e a montante (fornecedores) na cadeia. Essa mudança dos mecanismos de desempenho na cadeia de suprimentos representa um tema de significativa expansão nas empresas e nos estudos internacionais (BEAMON, 1998; NEELY et al., 2000 (SHEPHERD; GUNTER, 2006;
FABBE-COSTES; JAHRE, 2008; GREEN JUNIOR; WHITTEN; INMAN, 2008; RICHEY JUNIOR et al., 2009; PAPAKIRIAKOPOULOS; PRAMATARI, 2010; SONI; KODALI, 2010; TAN et al., 2010) e nacionais (SELLITTO; MENDES, 2006; McCORMACK; LADEIRA; OLIVEIRA, 2008; OLIVEIRA; MARTINS, 2008; RODRIGUES; SELLITTO, 2009; HILSDORF; ROTONDARO; PIRES, 2009; CUNHA; ZWICKER, 2009)

No sentido de entender esse conjunto de modificações, esse artigo tem por objetivo principal identificar a ocorrência e analisar as principais características da medição de desempenho em uma representativa cadeia de suprimentos da indústria automobilística brasileira, a qual utiliza um condomínio industrial.

Esse objetivo, posto sob a perspectiva de uma empresa foco, que é uma grande montadora de automóveis instalada no País há décadas e contemplando a utilização de um modelo de condomínio industrial em sua cadeia de suprimentos, tornam o objeto de estudo contemporâneo e representativo em termos de estado da arte sobre a questão.

Com o intuito de se atingir o objetivo estabelecido, 6 empresas, ao todo, fizeram parte da pesquisa. Para tal, foram entrevistados executivos responsáveis por 4 áreas básicas de interesse dentro das empresas pesquisadas, ou seja, das áreas de logística, suprimentos, produção e vendas.

Assim, o conjunto de 6 empresas estudadas compreendeu a montadora de automóveis, um fornecedor sistemista instalado dentro do condomínio da montadora, outros três fornecedores de autopeças localizados na mesma região geográfica da montadora e uma concessionária (ponto de venda). Posteriormente, quando do estudo de caso, o escopo do estudo será mais bem detalhado.

O estudo desses elos da cadeia permitiu entender a medição de desempenho em relações altamente colaborativas (caso do fornecedor sistemista), relações mais "tradicionais" na cadeia (outros fornecedores) e relações comerciais (concessionárias) ligadas diretamente aos clientes finais. Isso permitiu, então, comparar as diferentes posições das empresas na cadeia e os reflexos na medição de desempenho.

\section{Gestão da cadeia de suprimentos}

Uma cadeia de suprimentos abrange os processos entre fornecedores clientes desde a fonte inicial de matéria-prima até o ponto de consumo do produto acabado, ou seja, todas as funções dentro e fora de uma empresa que garantem que se possa fazer e providenciar produtos e serviços aos clientes finais (COX et al., 1995; PIRES, 2004). Em termos gerais, uma cadeia de suprimentos envolve um conjunto de empresas ordenadas de forma subsequentes 
e autônomas, ou semiautônomas, as quais são efetivamente responsáveis pela obtenção, produção e liberação de um determinado produto e/ou serviço ao cliente final (PIRES, 2004).

Em uma cadeia de suprimentos, uma determinada empresa (tomada como foco) atua com um conjunto de fornecedores diretos (first tier suppliers) e esses últimos com outros, ou seja, o fornecedor desses fornecedores (second tier suppliers) e assim por diante. Essa empresa também possui um conjunto de clientes com os quais se relaciona de forma direta e outros com os quais se relaciona de forma indireta. Assim, a empresa foco mantém relações no sentido de seus fornecedores (montante - upstream) e no sentido do cliente final (jusante - downstream) (PIRES, 2004).

Autores como Lambert, Cooper e Pagh (1998) também sugerem a classificação dos membros de uma cadeia de suprimentos em primários e de apoio. Os membros primários são aquelas empresas ou unidades de negócios que executam atividades que agregam valor a um determinado produto e/ou serviço, enquanto que a os membros de apoio são representados pelas empresas que fornecem recursos, conhecimento, etc., que suportam os membros primários da cadeia, porém não participam diretamente no processo de agregação de valor. Slack (1993) também divide uma cadeia de suprimentos em três partes que são: a cadeia interna (dentro da empresa foco), a cadeia imediata (fornecedores e clientes imediatos) e a cadeia total. Lambert, Cooper e Pagh (1998) citam três elementos inter-relacionados: a estrutura, o processo e os componentes para a SCM. A estrutura da cadeia envolve os tipos dos atores, a estrutura vertical, a estrutura horizontal e o posicionamento horizontal das organizações da cadeia de fornecedores. Os processos de negócios são estruturas de atividades dimensionadas para adicionar valor ao produto final. O gerenciamento dos componentes da cadeia envolve atividades gerenciais em que os processos de negócios são integrados e geridos ao longo da cadeia.

Por sua vez o conceito de Gestão da Cadeia de Suprimentos (Supply Chain Management - SCM) pode ser tomado como um modelo gerencial contemporâneo que vai além da logística ao integrar as operações de negócios e a gestão de processos-chave na cadeia de suprimentos desde o desenvolvimento de produtos até o pós venda. Desse modo, pode-se afirmar que a gestão da cadeia de suprimentos é multifuncional, envolvendo áreas diversas como gestão da produção, marketing, compras e logística, requerendo assim uma abordagem sistêmica (PIRES, 2004). Dessa forma a SCM busca integrar todos os atores e as relações produtivas da cadeia, com o objetivo de atender o cliente final de maneira mais eficiente e eficaz possível.

Outro conceito inserido no contexto da SCM é o de governança na cadeia. Para Suzigan, Garcia e
Furtado (2002), a governança refere-se ao grau de hierarquia, liderança e comando (ou, alternativamente, colaboração e cooperação) entre os atores. Storper e Harrison (1991) entendem a governança a partir do "ator que exerce poder de afetar o desenvolvimento do sistema". No geral, essas relações podem ser governadas por mecanismos de mercado ou por processos de cooperação conformado por mecanismo de controle e desempenho.

\section{Medição de desempenho em cadeias de suprimentos}

A necessidade de medição e avaliação de desempenho foi evidenciada logo no início da chamada produção em massa, com o desenvolvimento e racionalização dos processos produtivos. Conforme citam Brandão e Guimarães (2001), o primeiro tipo de sistema de medição estabelecido foi criado por Taylor no processo de racionalização do trabalho, apresentando as primeiras escalas de "avaliação de mérito". Também no chamado modelo de Fayol, havia sistemas de controle e de desempenho (MOTTA; VASCONCELOS, 2005). Esse período foi o início do surgimento de várias formas e sistemas de medição de desempenho nas empresas. Logo após, surgiu o gerenciamento contábil, que era composto por medidas que tinham por objetivo mensurar o retorno financeiro. Esse tipo de medida surgiu em resposta à mudança da natureza do mercado e à perspectiva de maiores lucros por meio da produção centralizada e não artesanal (WAGGONER; NELLY; KENNERLEY, 1999).

Entretanto, uma mudança maior nos sistemas de medição ocorreu de fato quando executivos sentiram necessidade de instrumentos ou sistemas que pudessem assegurar a manutenção das estratégias da organização (ECCLES, 2000). Entre 1980 e 1990, surgiram as medidas de desempenho relacionadas à qualidade $\mathrm{e}$ satisfação do cliente (ECCLES, 2000). A necessidade de controlar o desempenho da estratégia, da qualidade e da satisfação dos clientes surgiu porque fatores externos, como clientes e concorrentes, passaram a interferir significativamente no posicionamento estratégico das organizações. Segundo Nauri (1998), um sistema de medição de desempenho (SMD) busca estabelecer o grau de evolução, estagnação ou decadência de determinados processos. Os SMD também devem fornecer informações refinadas para o processo de tomada de decisão sobre ações preventivas e/ou corretivas. Geralmente a medição de desempenho é considerada essencial para se manter altos níveis de qualidade e produtividade, proporcionar um bom controle e gerenciamento, e ainda desenvolver e motivar a organização (KAYDOS, 1991).

Assim, durante décadas, a questão da medição de desempenho foi abordada sob uma perspectiva interna às empresas. Entretanto, isso ganhou novas implicações nas últimas duas décadas com o surgimento e expansão 
do conceito de SCM. Nesse contexto, Pires (2004) ressalta que uma significante mudança de paradigma competitivo e gerencial ocorrido com o surgimento e expansão do conceito de SCM é a constatação de que a competição empresarial tende a ocorrer cada vez mais entre cadeias de suprimentos e não mais apenas entre empresas isoladas. Assim, considerando-se que muito da conceitual desenvolvida sobre a questão da medição de desempenho foi construída a partir de empresas vistas de forma isolada (perspectiva interna), surgiu então uma demanda de revisão e/ou de readequação do conhecimento na área. Nessa linha, o referido autor ressalta que alguns autores são categóricos ao afirmarem que a SCM também precisa incorporar um novo sistema de medição de desempenho, como apresentado por outros diversos autores (SELLITTO; MENDES, 2006; SHEPHERD; GUNTER, 2006; FABBE-COSTES; JAHRE, 2008; McCORMACK; LADEIRA; OLIVEIRA, 2008; GREEN JUNIOR; WHITTEN; INMAN, 2008; RICHEY JUNIOR et al., 2009; RODRIGUES; SELLITTO, 2009; HILSDORF; ROTONDARO; PIRES, 2009; PAPAKIRIAKOPOULOS; PRAMATARI, 2010; SONI; KODALI, 2010; TAN et al., 2010; CUNHA; ZWICKER, 2009).

Entretanto, muitos sistemas utilizados em cadeias de suprimentos têm ainda um foco interno e não medem o desempenho da cadeia como um todo, conforme mencionam Lambert e Pohlen (2001). Outros autores lembram a carência de estudos sobre a medição de desempenho na cadeia de suprimentos (BEAMON, 1999; GUNASEKARAN; PATEL; TIRTIROGLU, 2001; HOLMBERG, 2000). Segundo Lambert e Pohlen (2001), a falta de medidas próprias para a cadeia de suprimentos pode resultar em falhas para alcançar as expectativas do cliente, subotimizações na cadeia, barreiras para o alcance de vantagens competitivas e geração de conflitos entre empresas participantes. Por sua vez, a integração das medidas de desempenho em toda a cadeia de suprimento pode permitir a avaliação do desempenho global e identificar os melhoramentos internos que devem ser realizados para se obter impactos na competitividade da empresa (CROXTON et al., 2001). Já Beamon (1999) ressalta que a escolha de medidas de desempenho para a cadeia é complexa porque depende de muitos fatores, tais como tamanho, cultura, necessidades, localização, entre outros fatores. Nessa linha, sugere algumas características relevantes para a análise do sistema de medição de desempenho da cadeia: abrangência (medição de todos os aspectos pertinentes); universalidade (permitir a comparação entre os diferentes níveis); mensurabilidade (os dados necessários podem ser medidos); e consistência (medidas consistentes com as metas estratégicas). Essas características garantem ao sistema de medição consistência e confiabilidade.
Por sua vez, as questões referentes à medida de desempenho voltadas à cadeia, citadas por Pires (2004), envolvem atendimento ao pedido, satisfação do cliente, qualidade do produto, lead time do atendimento ao pedido, custo, tempo de fluxo entre os desembolsos e receitas, volume de estoque, desempenho dos ativos. Outras questões apontadas por outros autores envolvem o tempo de desenvolvimento e lançamento de produtos, a obsolescência, queixas de consumidores finais, itens danificados, tempo de ciclo de desenvolvimento de produtos, método de entrada dos pedidos, tempo total do ciclo ao longo da cadeia, tempo total de fluxo de caixa, mix de produtos e de serviços, custos dos sistemas de informação, retorno sobre investimentos, desempenho das entregas, entregas sem defeito, habilidades para resolver problemas de qualidade, tempo de ciclo de compras, iniciativa de redução de custo, custo de produção, utilização da capacidade, efetividade do programa mestre de produção, tempo de ciclo de produção, nível dos estoques de matéria-prima em processos e de bens acabados, taxa de perdas durante o ciclo produtivo, lead time de entrega, número de entregas com problemas, custo total de distribuição, flexibilidade no atendimento às necessidades dos clientes nível de satisfação dos clientes, entre outros aspectos (SHEPHERD; GUNTER, 2006; RITCHIE; BRINDLEY, 2007; GULLEDGE; CHAVUSHOLU, 2008; CHIA et al., 2009).

Nesse contexto, o papel da indústria automobilística é bastante relevante. Considerando então o papel de liderança exercido por esse segmento industrial em termos de expansão da SCM e o fato das montadoras automobilísticas restringirem cada vez mais seu foco a um conjunto-chave de atividades (com o consequente aumento do repasse de atividades para seus fornecedores) a questão da medição de desempenho na cadeia de suprimentos adquire uma grande relevância no setor.

\section{Estudo de caso}

Conforme já ressaltado, o estudo de caso realizado envolveu uma montadora de automóveis (empresa focal do estudo), utilizando uma fábrica configurada na forma de um condomínio industrial, dois fornecedores de primeira camada (empresas A e B), dois fornecedores de segunda camada (empresas C e D) e uma concessionária (ponto de venda) de veículos. A Figura 1 delimita o escopo da cadeia de suprimentos, a qual inclui empresas posicionadas tanto no inbound (montante), como no outbound (jusante) da empresa focal (montadora) estudada, o que constitui um representativo e atual objeto de estudo.

Em termos metodológicos, a pesquisa foi de caráter exploratório e descritivo. A coleta de dados foi realizada durante $2009 / 10$ por meio de entrevistas (seguindo um questionário semiestruturado previamente desenvolvido) com os executivos 


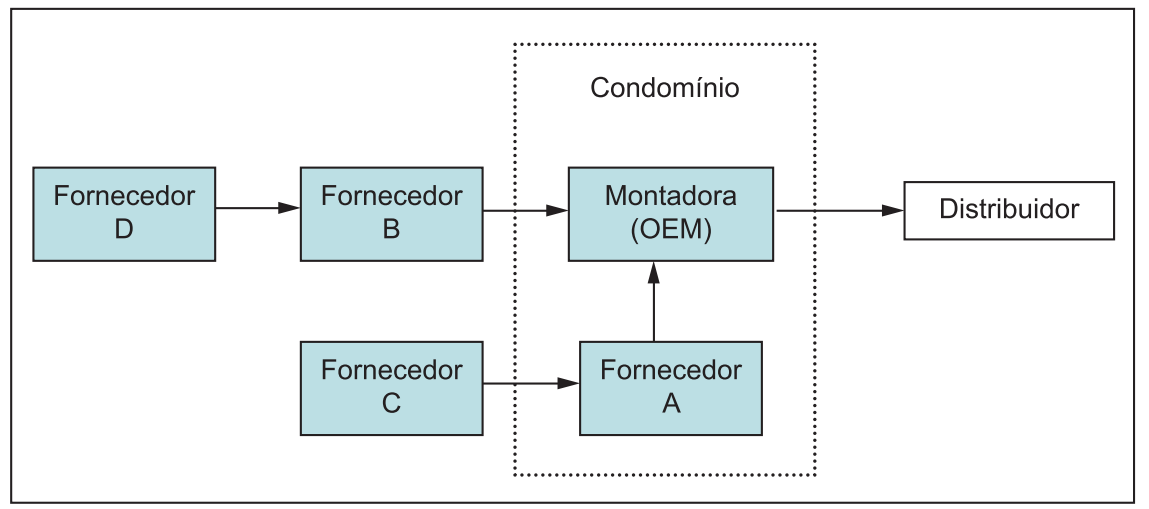

Figura 1. Delimitação da cadeia de suprimentos estudada.

responsáveis pelas áreas de suprimentos, produção, vendas e de logística, tanto na montadora como nos fornecedores de autopeças. As entrevistas sempre foram complementadas com uma visita in loco às principais operações produtivas e logísticas das plantas estudadas. Na concessionária (distribuidor), a entrevista foi desenvolvida com o diretor comercial.

Um aspecto interessante da cadeia estudada é o fato de que o fornecedor A é um fornecedor "sistemista" instalado dentro da planta da montadora. Um elemento verificado e explorado no estudo é a diferença da natureza das relações (conexões) da montadora com um sistemista e da montadora com os fornecedores tradicionais. Por esse fato, a pesquisa incorporou a análise desde os fornecedores de segunda camada até as concessionárias de veículos, delimitando um escopo de pesquisa mais rico e pouco comum em trabalhos na área uma vez que os trabalhos publicados em SCM geralmente se limitam a dois elos da cadeia. Esse fato gerou tipos de conexões e medidas de desempenho distintas em uma mesma cadeia de suprimentos. Isso foi explorado na análise dos resultados da pesquisa.

\subsection{Descrição das empresas estudadas}

A seguir será realizada uma breve descrição das empresas pesquisadas.

\subsubsection{A montadora e o condomínio industrial (empresa focal)}

A fábrica estudada da montadora é um dos ícones da indústria automotiva e da industrialização brasileira. No ano de 2002, a planta foi reformulada para se tornar um condomínio industrial. Conforme relata Pires (2004), no condomínio industrial os fornecedores-chave estão instalados fisicamente ao lado da montadora para abastecer seu sistema produtivo. Os fornecedores sistemistas estão fisicamente localizados no condomínio da montadora e possuem um relacionamento estreito e colaborativo com a montadora no desenvolvimento de produtos e planejamento da produção. O nível de interdependência neste tipo de relacionamento é alto e envolvendo elevados investimentos de ambas as partes.

A logística da fábrica tem elevada complexidade. Existem diferentes tipos de fornecedores: aqueles responsáveis em abastecer a linha no ponto de uso, sendo assim responsáveis pelas questões referentes ao transporte e armazenagem. Mas também, existem os fornecedores que não são responsáveis pelo transporte, pois a montadora se encarrega dessa atividade por meio de um operador logístico. Outro fator responsável por agravar a complexidade do sistema é o número de componentes, que gira em torno de 4.000 por tipo de plataforma. Este número é variável, porque o automóvel sofre constantes mudanças, sejam elas bruscas ou quase imperceptíveis. Considerando todas as plataformas presentes na planta, o total de componentes a ser gerenciado pela montadora é estimado em 25.000. Segundo a montadora, caso não existissem os sistemistas, esse número seria aproximadamente 40.000 componentes.

Para lidar com baixos níveis de estoque e elevada flexibilidade do sistema de produção, a montadora utiliza várias práticas logísticas contemporâneas como o milk run, o cross docking e o just in sequence. A montadora produz majoritariamente no sistema make to order (produzir sob pedido - MTO). Cabe aqui destacar que no sistema MTO as informações sobre as características do produto que deve ser fabricado são tradicionalmente originárias do cliente final. Mas, neste caso, as informações sobre quais as características do produto vêm da sua área comercial ou da concessionária de veículos, caracterizados como clientes imediatos do sistema.

\subsubsection{Os fornecedores e a concessionária}

$\mathrm{O}$ estudo envolveu quatro fornecedores da montadora e um de suas concessionárias conforme se segue. 
- Fornecedor A: O fornecedor A é um sistemista instalado dentro da planta da montadora a qual emprega 40 funcionários. O fornecedor pertence a um grupo alemão que atua no ramo automobilístico, fornecendo peças e sistemas para carroceria, chassis e motores (sistemas powertrain). No Brasil, o grupo tem 22 subsidiárias e emprega em torno de 9.000 pessoas.

- Fornecedor B: O fornecedor B, pertence a um grupo alemão, desenvolve e produz fechaduras mecânicas e eletrônicas para a indústria automotiva. Mais de 200 designers trabalham na Alemanha, EUA e Coreia desenvolvendo componentes para acesso aos carros e sistemas de imobilização do tipo "entrada passiva". No Brasil, a planta se instalou no interior do Estado de São Paulo e fornece diretamente à montadora em questão.

- Fornecedor C: $\mathrm{O}$ fornecedor $\mathrm{C}$ também pertence a um grupo alemão que atua no segmento automobilístico, manufatura de tubos, engenharia mecânica e distribuição. No ramo automotivo, a empresa desenvolve e produz módulos completos, componentes para a carroceria, chassis e motores. Esse fornecedor de autopeças veio ao Brasil em 1999 em função de um follow sourcing estabelecido com duas montadoras.

- Fornecedor D: O fornecedor D é uma empresa nacional que providencia estampados e ferramentas de corte e repuxo ao fornecedor B. Fornece também para outras empresas, em sua grande maioria, fornecedores da indústria automobilística. A empresa foi fundada em 1983 no interior do Estado de São Paulo e hoje emprega 19 pessoas.

- Concessionária: A concessionária estudada pertence a um grupo empresarial que atua no interior do Estado de São Paulo e em Minas Gerais. $\mathrm{O}$ grupo tem ao todo 6 concessionárias (pontos e venda).

\subsection{Avaliação no sentido montante}

Nesta etapa, são apresentados os principais aspectos referentes à medição de desempenho no sentido montante da cadeia de suprimentos, visto sob as perspectivas tanto da montadora como dos quatro fornecedores.

\subsubsection{Visão da montadora}

A avaliação desempenho dos fornecedores é considerada uma questão relevante para a montadora, conforme diversos depoimentos no decorrer da pesquisa. A avaliação dos fornecedores é realizada de forma multifuncional, possuindo pesos de medição diferentes para as áreas de logística, engenharia, qualidade, finanças e comercial, conforme constatado nas entrevistas.

A logística é responsável pela avaliação de aspectos operacionais do fornecedor como: (1) facilidade no fluxo de informações, (2) tipo de embalagem, (3) forma de transporte e armazenagem e (4) nível de atendimento no que se refere ao cumprimento da programação e entregas no prazo (on time). A logística também é responsável pela disposição do produto no ponto de uso e ao atendimento ao programa mestre de produção da montadora. Conforme relatado pelos executivos, a operação logística de forma eficiente garante uma produção sincronizada e níveis adequados de estoque.

A Engenharia verifica o potencial de desenvolvimento de produtos e processos, qualidade do processo e disponibiliza alguns meios de controle na análise e seleção de fornecedores. Os processos mais técnicos relacionados à avaliação de fornecedores são encontrados nesta área.

A Qualidade contempla o sistema que garantia a qualidade de processo (processo interno, meios de controle, aferição de ferramental e manutenção). A área possui o poder de veto na avaliação de fornecedores, porque este requisito é considerado qualificador de pedido. Uma prioridade competitiva qualificadora de pedido significa que a característica requerida deve ser intrínseca ao produto ou componente. Os dois aspectos mais relevantes nesta área são: a conformidade do produto e o atendimento das especificações da montadora.

A área de Finanças também participa da avaliação dos fornecedores analisando se eles possuem a lucratividade e "saúde financeira" necessária para se manter no negócio. Esse é considerado um aspecto importante, pois, se o fornecedor não possuir equilíbrio financeiro, pode comprometer questões como a qualidade do produto e/ou o desempenho de entrega.

A última área que participa deste processo é uma equipe representando Compras/Comercial, a qual estuda e monitora a intensidade e formas de relacionamento entre os fornecedores e a empresa. Esta também analisa qual foi a contribuição da produtividade do fornecedor para a redução de preços no produto final.

No geral, se um fornecedor for vetado por alguma área, mas se for constatado que este possui potencial de fornecimento, planos de ação são lançados para capacitá-lo. Também, as cinco áreas que compõem a avaliação de desempenho centralizam as informações em reuniões semanais, denominadas de "fóruns de definição dos fornecedores". Essas reuniões acontecem duas vezes por semana e contam com representantes das áreas descritas anteriormente. 
Na definição de novos fornecedores para um novo projeto, ocorrem duas reuniões dentro dos "fóruns de definição dos fornecedores". O setor de Compras indica os fornecedores aptos para o fornecimento e, na primeira reunião, levantam-se as cotações de preços via internet, que pré-definem os fornecedores que irão participar do processo. $\mathrm{Na}$ segunda reunião, os fornecedores são avaliados por cada área e uma decisão conjunta é tomada para escolher os melhores fornecedores. Questões como qualidade e desempenho de entregas são características importantes na avaliação de fornecedores, conforme o depoimento dos entrevistados. Entretanto, a prioridade competitiva que assume a posição de ganhador de pedido quase sempre é o custo.

\subsubsection{Visão dos fornecedores}

Os fornecedores também dispõem de sistemas de medição de desempenho internos, que acabem se desdobrando em medidas externas.

$\mathrm{O}$ fornecedor $\mathrm{A}$ tem diversos indicadores de desempenho, como vendas físicas, reclamações dos clientes, falhas de campo, parada de linha do cliente, tempo médio de falhas, controle de desperdício e refugo, material bloqueado pelos fornecedores, auditoria do produto e controle de manutenção. Os critérios diretamente relacionados à cadeia de suprimentos da montadora são reclamações do cliente e parada de linha do cliente. $\mathrm{O}$ fornecedor A considera que tem um sistema de medição de desempenho interno mais rigoroso do que o utilizado pela própria montadora para medir o desempenho dos fornecedores. Ele considera que a montadora de fato mede a qualidade e uma eventual e indesejada parada da linha final de montagem.

Assim como a montadora, o fornecedor B também utiliza diversos indicadores de desempenho internos, como: desempenho de entregas, número de defeitos, relacionamento com o cliente, faturamento, custo da mão de obra, volume de vendas, giro de inventários, percentual de compras sobre o faturamento, custo da não conformidade, qualidade, pontualidade e precisão das entregas, produtividade, perda de matéria-prima e eficiência fabril. Esses critérios geram informações referentes ao desempenho das áreas de Logística, Qualidade e Finanças. Entretanto, a empresa considera que a montadora controla, prioritariamente, a qualidade e o desempenho das entregas (pontualidade, flexibilidade, transporte, embalagem, atendimento e precisão das entregas).

Da mesma forma, o fornecedor $\mathrm{C}$ é avaliado pela montadora em questões de qualidade e desempenho das entregas. Semestralmente, o fornecedor $\mathrm{C}$ recebe uma avaliação da montadora informando o desempenho das entregas e mensalmente recebe a avaliação da qualidade dos itens fornecidos. A qualidade e desempenho das entregas são os dois principais critérios avaliados (pelo fornecedor B) no fornecedor D. Os tipos de informações trocadas limitam-se às questões de projeto e programação (tipo de peça, quantidades e datas).

Um problema apontado pelo fornecedor D é a reprogramação da produção que gera problemas de planejamento, acarretando, muitas vezes, atraso de entrega. Esse é um dos reflexos do efeito chicote na cadeia, prejudicando os elos a montante. As exigências de desempenho do fornecedor $\mathrm{B}$, para o fornecedor $\mathrm{D}$, envolvem: especificação do número de pedido na nota, quantidade e tipo de peça.

Na cadeia de suprimentos estudada, a relação com o fornecedor D é claramente caracterizada como a de menor intensidade no relacionamento entre as empresas, pois se trata de peças estampadas, de pouco valor agregado e praticamente uma commodity no setor automobilístico. Isso reflete significativamente no relacionamento entre as empresas e também na forma de se medir o desempenho. A Figura 2 ilustra o nível de integração de processos e medidas de desempenho em função do valor agregado pelos quatro fornecedores estudados.

Observa-se que quanto maior o valor agregado das peças fornecidas, maiores serão os níveis de integração de processos e avaliação de desempenho, como ocorre no elo com o fornecedor A, no qual há elevada parceria, mas também maiores critérios de desempenho. Isso se deve ao fato de que o fornecedor A e a montadora compartilham de elevada interdependência de seus processos, acarretando em maiores exigências de desempenho, embora o nível de confiança e comprometimento seja alto.

\subsection{Avaliação no sentido jusante}

Nesta etapa, são apresentados os principais aspectos referentes sobre a medição de desempenho no sentido jusante da cadeia de suprimentos, visto sob as perspectivas tanto da montadora como da concessionária.

Aqui os dados obtidos nas entrevistas com a área comercial da montadora e com a concessionária serão apresentados de forma conjunta, uma vez que a separação entre elas tornaria a apresentação muito repetitiva.

A área comercial da montadora faz a ligação entre a montadora e as concessionárias com o objetivo de atender à demanda do cliente final com relação ao atendimento das conformidades e do desempenho das entregas. A área comercial envolvida neste estudo é responsável pela regional abrangendo: São Paulo capital e o ABC Paulista (representada por 40 concessionárias). No interior do Estado de São Paulo, a montadora estudada abrange mais de 100 concessionárias. No total, a empresa é representada 


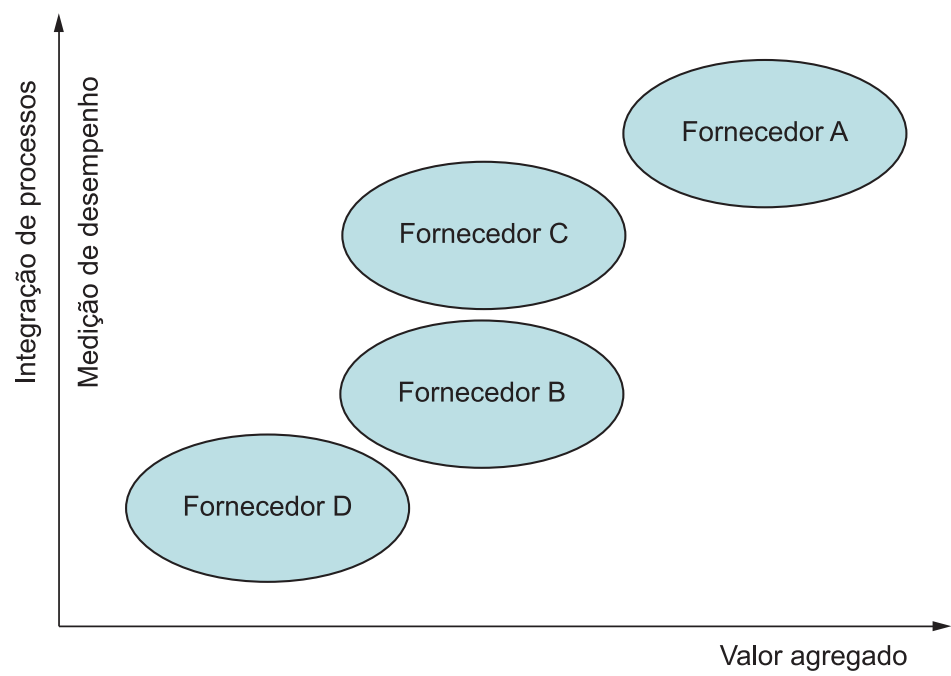

Figura 2. Integração de processos e medidas de desempenho em função do valor agregado pelos fornecedores estudados.

por 6 regionais que compreendem toda sua parte comercial (vendas) no País.

Conforme relatado nas entrevistas, pelas leis brasileiras, a montadora não pode realizar vendas diretas ao consumidor final. Então, as concessionárias são os canais de distribuição para atender à demanda dos clientes. Por isso, a montadora tem grande interesse e necessidade em monitorar e avaliar o desempenho das concessionárias, pois, de forma indireta, busca melhorar o desempenho das concessionárias e avaliar como os clientes estão sendo atendidos.

O relacionamento entre área comercial e manufatura da montadora define os modelos de veículos a serem produzidos. No passado, o relacionamento entre área comercial e manufatura era representado pela dualidade de metas. Enquanto a área de manufatura queria simplificar a produção, a área comercial procurava vender "o que o cliente queria". Isso causava problemas interdepartamentais críticos, conforme relatado. Atualmente, esse relacionamento é mais integrado, efetivo e com resolução de problemas em conjunto.

A montadora impõe para as concessionárias um lote mínimo de compra de veículos básicos e outro lote composto de veículos "encomendados" pela concessionária. A função da área comercial é intermediar a gestão dos pedidos e também realizar a ligação entre uma produção viável e o completo atendimento da demanda. A troca e o compartilhamento de informações são integrados entre a montadora, a área comercial e as concessionárias. A concessionária pode acessar as informações sobre os programas de produção da montadora para as próximas cinco semanas. E a montadora pode obter informações sobre os veículos disponíveis na concessionária por meio deste mesmo sistema de informações. Essa integração de informações permite otimizar estoques e elevar o nível de serviço das concessionárias.

A integração entre a área comercial da montadora e as concessionárias é necessária e bem evidente no caso estudado. São realizadas reuniões mensais entre a área comercial e as grandes concessionárias para a definição de políticas e estratégias mercadológicas. Cada concessionária possui uma estratégia diferente, porque está localizada em uma área específica com clientes-alvo distintos.

Com o intuito de se melhorar o atendimento às demandas dos clientes, várias iniciativas foram implementadas pela montadora nos últimos anos. Uma das principais medidas, foi a reestruturação da base de concessionárias. Como consequência, o relacionamento entre a montadora (representado pela área comercial) e as concessionárias vem se intensificando. A área comercial da montadora não mede apenas o desempenho da concessionária, mas também interfere nas políticas de gestão.

A montadora tem designado consultores para as concessionárias para analisar e propor mudanças, desde atividades administrativas, até de fidelização do cliente. Esse suporte técnico e administrativo prestado pelas montadoras às concessionárias ocorre de duas formas: back-office e front-office. O back-office é caracterizado por consultores que analisam e propõem planos de ação que vão desde as questões relacionadas ao nível de atendimento até a administração da concessionária. Os consultores podem ser classificados em três tipos: de mercado, de distribuição e de negócios. O front-office da regional de São Paulo é composto por quatro subgerentes que administram e monitoram as 40 concessionárias sob a responsabilidade da regional. De certa forma, eles podem ser considerados um elemento in loco de suporte para o back-office nas concessionárias. 
Vários são os indicadores de desempenho das concessionárias. Os três principais indicadores mais analisados pela área comercial são : (1) Desempenho de Vendas, (2) Atendimento ao Cliente e (3) Rentabilidade Mensal do Negócio.

O desempenho de vendas indica o potencial de crescimento e desenvolvimento da concessionária. Esse indicador normalmente está vinculado com os indicadores de atendimento ao cliente e rentabilidade. A área comercial direciona grandes esforços para manter os níveis de atendimento ao cliente das concessionárias. Atualmente, não é interessante para a montadora apenas a concessionária comercializar elevadas quantidades de veículos. Interessa também à montadora, como o cliente está sendo atendido e os níveis de rentabilidade do negócio. Concessionárias com curtos ciclos de vida, além de prejudicar a marca do veículo, são pressionadas para serem compradas por grupos maiores.

A montadora estudada mede a satisfação do cliente da concessionária por meio de um sistema denominado SIQ (Sistema de Informação de Qualidade). Esse sistema é responsável pela medição de aspectos relacionados à satisfação do cliente em termos de vendas e serviços das concessionárias. A satisfação do cliente além de ser medida pelo SIQ, coletado por meio de um questionário enviado diretamente ao domicílio do cliente. O SIQ também é medido por meio de um representante, disfarçado de cliente, enviado frequentemente pela montadora para visitar concessionárias. Por meio do SIQ, a concessionária e a montadora identificam se o cliente está satisfeito. Se não estiver, diagnósticos são realizados e elaboram-se planos de ação para melhorar o nível de satisfação. Os indicadores considerados nos SIQ são: satisfação geral do cliente, satisfação com as vendas, satisfação com os serviços, características do show-room, avaliação do vendedor, avaliação do preço do usado, entrega do veículo, acompanhamento após compras, qualidade do reparo, tratamento dispensado ao cliente, preço do reparo, prazo de entrega e ofertas. Por meio desse monitoramento do pós-venda, a montadora realiza um diagnóstico para verificar os pontos críticos a serem melhorados nas concessionárias.

\subsection{Análise da medição de desempenho na cadeia estudada}

De uma forma geral, o estudo realizado mostra que não foi identificada uma sistemática única e integrada para medição da cadeia de suprimentos estudada. De forma similar, em uma vasta pesquisa com 71 artigos publicados em periódicos renomados, sobre a relação entre integração e desempenho, (FABBE-COSTES; JAHRE, 2008) destacam muitos estudos com resultados contraditórios sobre integração e desempenho na cadeia. Isso mostra o vasto campo de estudo para outros estudos.

A empresa focal (montadora) tem sistemas internos de medidas de desempenho, os quais se desdobram para a cadeia de suprimentos a montante (fornecedores) e a jusante (concessionária) e que são originados em diferentes setores da empresa. Assim, a montante, as áreas de Logística e Qualidade têm maior influência nas políticas de abastecimento e, a jusante, a área Comercial/Vendas tem maior influência sobre as concessionárias, como já era naturalmente esperado.

Por sua vez, os fornecedores também têm medidas de desempenho internas. As medidas de desempenho dos fornecedores quanto à Logística e Qualidade são fortemente influenciadas pelas exigências das montadoras. A montadora direciona todo o processo de medição de desempenho da cadeia, exercendo a coordenação dos principais critérios de medição de desempenho. Assim, o sistema interno da montadora permite consolidar várias informações no sentido de medir o desempenho a montante e jusante e consequentemente no âmbito da cadeia. Esse conjunto de medidas parte de indicadores internos da montadora e também dos fóruns de definição de fornecedores. Esses fóruns são compostos de forma multifuncional e avaliam o desempenho e definem fornecedores de projetos atuais e futuros da montadora.

A montadora mede e avalia o desempenho interno por meio de um conjunto consistente de indicadores denominados por ela de KPIs (Key Performance Indicators), o qual abrange todas suas áreas e colaboradores internos. Os critérios e metas são desdobrados de objetivos corporativos agregados para áreas específicas (como as diretorias, departamentos, setores, etc.). Dentro da empresa, os critérios de desempenho são sempre sinalizados por cores verde, amarelo e vermelho com limites de controle bem definidos. Quem consolida e divulga esses números é a área de Controladoria.

Por sua vez, a área de Logística da montadora faz uso de um conjunto de dez indicadores-chave que são: porcentagem de produção perdida, consistência da lista de materiais (bill of material), volumes de rejeitos, cripple (número de unidades faltantes/veículos incompletos), níveis de inventários, entregas de peças de reposição, overtime (pagamento de pessoal direto ou mensalista), custo logístico (compra de insumos), overhead e volume e fidelidade do inventário. Analogamente, outras áreas funcionais da empresa têm essa mesma cobertura por meio dos desdobramentos do sistema e cada um de seus funcionários têm sua folha de KPI e critérios que agregam valor na área.

Algumas medidas de desempenho da área de Logística se desdobram até os fornecedores. Uma das medidas de desempenho típica de desdobramento é o cripple, que indica que no veículo montado está faltando alguma peça e, consequentemente, indica 
as falhas ao longo da cadeia de suprimentos. Assim, mesmo indiretamente, os KPI acabam refletindo nos fornecedores. Os reflexos dos KPI nos fornecedores sistemistas são discutidos diariamente na montadora, em reuniões em que são decididas ações preventivas e corretivas.

De certa forma, o sistema de medição de desempenho interno da montadora se assemelha ao Balanced Scorecard (BSC), principalmente no tocante aos desdobramentos das metas até chegar à definição dos indicadores a serem utilizados nas diversas áreas da empresa. A corporação à qual pertence a montadora define sua estratégia e posteriormente delimita os objetivos a serem alcançados e desdobrados para as áreas funcionais. Isso corrobora a afirmação de Hronec (1994) acerca de que as medidas de desempenho devem ser desenvolvidas no nível corporativo e relacionar-se com a estratégia. Entretanto, isso ocorre internamente à montadora. Por outro lado, o alinhamento da estratégia e das medidas de desempenho no nível da cadeia envolve grande complexidade de interesses e variáveis.

Segundo Pires (2004), existem algumas barreiras para se identificar e implementar a estratégia no âmbito da cadeia: (1) em cada elo predomina, de fato, a estratégia interna da empresa que representa o elo, a qual é derivada da sua atuação no mercado e na competência interna, e que não necessariamente está ligada a uma estratégia considerada como sendo da cadeia; (2) a estratégia do elo mais forte da cadeia pode influenciar todas as outras estratégias dos outros elos da mesma cadeia; e (3) a participação de diversos elos em diversas cadeias de suprimentos dificulta a implementação de uma estratégia única ao longo da cadeia. Esses entraves dificultam o alinhamento das estratégias e também o desenvolvimento de medidas de desempenho entre empresas da cadeia. Por exemplo, com relação aos sistemas de qualidade, cada montadora instalada no País costuma adotar um modelo distinto, o que cria várias dificuldades aos fornecedores que tem de se adequar aos diferentes sistemas para garantir o fornecimento.

Por sua vez, as concessionárias, por atuarem próximas ao cliente final, têm mais condições de identificar novas necessidades e assim realinhar sua estratégia. A satisfação do cliente é uma medida multidimensional que avalia vários aspectos como qualidade (sob várias perspectivas), custo, flexibilidade e, até mesmo, fatores intangíveis como confiança. Assim, medidas relacionadas à satisfação do cliente final foram amplamente encontradas nas relações a jusante da montadora, ou seja, com suas concessionárias.

As entrevistas realizadas na montadora também realçaram sua preocupação em mensurar apenas empresas (elos) considerados estratégicos. Os fornecedores de segunda camada participam da avaliação de desempenho apenas quando algum problema sério com o produto é detectado pela montadora ou por um fornecedor de primeira camada. Nesse sentido, o que mais motiva a avaliação do fornecedor de segunda camada é a falta de qualidade referente a conformidade e especificações técnicas no geral.

De forma resumida, o Quadro 1 relata outros aspectos referentes à medição de desempenho a montante e a jusante da empresa focal estudada.

O estudo também corrobora as afirmações de Slack (1993) e Lambert e Pohlen (2001) de que, para se manter a efetividade de uma cadeia de suprimentos, muitas empresas têm considerado ser suficiente (pelo menos por enquanto) medir o desempenho apenas das empresas que compõem a chamada cadeia imediata da empresa foco (ou seja, seus fornecedores e clientes imediatos). De uma forma geral, é exatamente isso que ocorre com a montadora estudada, em especial no tocante a sua relação com o fornecedor sistemista, o qual apresenta maior integração de processos

Quadro 1. Medição de desempenho a montante e a jusante da empresa focal.

\begin{tabular}{|c|l|}
\hline Medição de desempenho & \multicolumn{1}{c|}{ Principais fatores envolvidos na medição de desempenho } \\
\hline \multirow{2}{*}{$\begin{array}{c}\text { Medidas de desempenho a } \\
\text { montante }\end{array}$} & $\begin{array}{l}\text { Áreas de logística, engenharia, qualidade, finanças e comercial formam os chamados } \\
\text { fóruns de seleção de fornecedores. Os sistemistas, em especial, têm outros critérios } \\
\text { de seleção e desempenho, como qualidade e influência numa eventual e indesejada } \\
\text { parada da linha final de montagem. O sistemista estudado é parceiro da empresa foco } \\
\text { na matriz. As medidas de desempenho a montante envolvem métricas operacionais e } \\
\text { técnicas dos fornecedores nas quatro áreas apontadas acima. }\end{array}$ \\
$\begin{array}{c}\text { A montadora avalia o desempenho de vendas, atendimento ao cliente, e rentabilidade } \\
\text { do negócio (análise mensal). A satisfação do cliente por meio do Sistema de } \\
\text { Informação de Qualidade (SIQ), incluindo: satisfação geral do cliente, satisfação } \\
\text { com os serviços, características do show-room, avaliação do vendedor, avaliação } \\
\text { do preço do usado, entrega do veículo, acompanhamento após compras, qualidade } \\
\text { dos reparos, tratamento dispensado ao cliente, preço dos reparos, prazo de entrega e } \\
\text { jusante } \\
\text { ofertas. No geral as medidas de desempenho a jusante visam medir desempenho das } \\
\text { concessionárias e a satisfação dos clientes. }\end{array}$ \\
\hline
\end{tabular}


e maior especificidade e detalhes na medição de desempenho. Tal procedimento, entretanto, continua sendo uma abordagem parcial em termos de medição de desempenho e que pode ser entendida apenas como um primeiro passo na trajetória de desenvolvimento dos sistemas de medição de desempenho de cadeias de suprimentos.

No caso estudado, o sistema de medição proporciona um forte comprometimento com o alcance das metas estratégicas determinadas pela alta direção da montadora. Esse comprometimento deve vir na forma de uma contribuição individual para o sistema e não deve ser encarado como forma de controle. Entretanto, as características de controle ainda são muito mais fortes nestes sistemas de medição de desempenho, principalmente nas relações mais tradicionais da montadora. Isso pode ser explicado pela forte influência que a montadora exerce tanto a montante quanto a jusante da cadeia. A montadora coordena e controla os principais canais de abastecimento e distribuição. Esse papel relaciona-se com a capacidade da montadora exercer a chamada governança na cadeia

No geral, a montadora possui duas formas de exercer essa governança e coordenação na cadeia: uma é realizada por meio de relações de mercado tradicionais (em que preço e qualidade são os critérios básicos) e a outra relação é aquela de elevada cooperação (relações pautadas em confiança e elevada troca de recursos), principalmente com os sistemistas e grandes concessionárias. No caso estudado, a montadora utiliza ambas as formas para garantir a estabilidade do conjunto de relações. Para os fornecedores de itens simples, a seleção é realizada por "leilões de fornecedores" cadastrados via internet, em que o critério básico é o preço e a qualidade, um critério qualificador. Já com os fornecedores sistemistas há um intenso conjunto de cooperação nas atividades para aprimorar os níveis de produtividade de ambas as plantas. Nessa relação, há elevada interdependência e elevados custos interempresariais em jogo.

Mesmo com relações mais colaborativas na cadeia, pode-se classificar a governança da montadora como core-ring with lead firm, conforme denominam Storper e Harrison (1991). Nesse sistema, a empresa líder tem substancial independência dos fornecedores e capacidade de reconfigurar parte dos subcontratados. O poder é assimétrico e há considerável hierarquia. Nesse sistema, a firma líder é dominante, isto é, os participantes dependem da estratégia do líder. Nesse sentido, autores como Gereffi (1999) ressaltam que geralmente a forma de governança na cadeia de suprimentos determina a alocação de recursos financeiros, materiais e humanos ao longo da cadeia. $\mathrm{O}$ estudo do impacto das relações de poder e governança na cadeia também foi sugerido por Daugherty (2011) como futuras pesquisas na área.
Assim, pode-se considerar que a montadora conseguiu legitimar, para alguns elos da cadeia, a governança baseada fortemente na imposição, pois exerce um grande poder econômico sobre os outros elos da cadeia. Já com elos que fornecem maior valor agregado (geralmente sistemistas), a governança é fortemente baseada na cooperação, mas com o uso mais intenso do sistema de medição de desempenho. Assim, as relações com o fornecedor sistemistas são mais amenas e providas de rotinas de cooperação conjunta. Resumindo, a legitimidade da governança é realizada por meio de uma combinação de sistemas de coerção e de cooperação.

\section{Considerações finais}

Conforme fora discutido, o crescimento do conceito de gestão da cadeia de suprimentos, criou a necessidade de revisão do conceito de medição de desempenho, visto agora sob a perspectiva da cadeia de suprimentos e não mais apenas de empresas isoladas. Mesmo assim, publicações acadêmicas relatando casos reais de medição de desempenho em cadeias de suprimentos ainda são raras, provavelmente em função das dificuldades encontradas para se realizar pesquisas que envolvam diversas empresas e/ou elos de uma cadeia de suprimentos. Nesse contexto, esta pesquisa contribui apresentando um estudo envolvendo três elos de uma cadeia de suprimentos na indústria automobilística e envolvendo uma montadora utilizando um contemporâneo condomínio industrial.

Com relação ao seu objetivo principal, e como já apontado anteriormente, não foi identificada a ocorrência de um sistema único de medição de desempenho da cadeia de suprimentos estudada. $\mathrm{O}$ constatado é que o sistema de medição de desempenho interno da montadora desdobra-se parcialmente a montante para os fornecedores e a jusante para os distribuidores. Os desdobramentos do sistema interno da montadora, somados à avaliação de fornecedores e das concessionárias e os fóruns de definição de fornecedores são suficientes para gerar diversos indicadores de desempenho restritos ao âmbito da chamada cadeia imediata.

A partir dos indicadores de desempenho utilizados pelas empresas estudadas e a partir da perspectiva da empresa foco (montadora), pode-se constatar que as medidas a montante são fortemente direcionadas para os aspectos operacionais relacionados à qualidade, produção e desempenho das entregas. Por outro lado, as medidas a jusante apresentam um caráter mais estratégico e mercadológico, recebendo também elevada atenção por parte da montadora.

Nota-se também que os indicadores de desempenho relacionados à cadeia (e desdobrados a partir da montadora) vão além dos tradicionais indicadores de custos, apresentando também indicadores que abrangem aspectos relacionados ao desempenho 
logístico, avaliação de fornecedores, capacidade de desenvolvimento de novos produtos e processos, satisfação dos clientes, entre outros. Adicionalmente, o que se poderia chamar de medição de desempenho da cadeia estudada (mesmo que se apresente de uma forma ainda não totalmente estruturada e formalizada) está majoritariamente contido na chamada cadeia imediata. Também, tem-se que a medição de desempenho na cadeia tende a ser mais intensa nos relacionamentos mais colaborativos, como é o caso da montadora com a empresa A. Os sistemas fornecidos pelo fornecedor A são de alto valor agregado, com elevadas especificidades e envolvendo características de segurança dos veículos. Um dos executivos de logística da montadora lembrou a facilidade de se lidar com os fornecedores sistemistas pela proximidade física. $\mathrm{O}$ fornecedor A, instalado fisicamente dentro da planta da montadora, apresenta um alto desempenho em todos os quesitos medidos pela montadora. Tal fato sugere que a configuração da cadeia de suprimentos é um fator determinante na forma como se dimensionam e controlam as medidas de desempenho na cadeia, o que se caracteriza um potencial tema carente de investigação.

Outra questão a ser realçada é a da governança na cadeia de suprimentos. No caso estudado, pode-se considerar que, pela assimetria de poder na cadeia, a montadora naturalmente impõe sua governança. Por outro lado, são nítidos seus progressos no sentido de maior cooperação com fornecedores-chave, como é o caso do fornecedor A.Por sua vez, o compartilhamento de informações sempre foi um elemento fundamental na construção de uma relação colaborativa. No caso estudado, o compartilhamento de informações ocorre com mais intensidade do sentido da cadeia imediata para a montadora. A montadora consegue ter acesso a vários tipos de informação, tanto no seu inbound como no outbound. A recíproca, na maior parte das vezes, não é verdadeira. No geral, pode-se considerar que o compartilhamento da informação ao longo da cadeia é fragmentado. Isso significa que a montadora trabalha com conteúdo e frequência de informação que não necessariamente são iguais com os elos da sua cadeia imediata, embora as informações básicas do seu programa mestre de produção sejam compartilhadas com todos os seus fornecedores imediatos.

Finalmente, cabe ainda ressaltar dois aspectos referentes à pesquisa realizada. $\mathrm{O}$ primeiro diz respeito às limitações inerentes ao método de estudo de casos, o qual limita os resultados da pesquisa apenas ao recorte estudado. Isso, entretanto, não significa que suas constatações não possam ser utilizadas como insights importantes derivados de uma pesquisa exploratória $\mathrm{O}$ segundo aspecto deve-se ao fato de que a cadeia de suprimentos imediata estudada apresentava uma configuração englobando uma grande montadora de automóveis, uma concessionária e quatro fornecedores situados em posições distintas, incluindo um sistemista. Isso proporcionou um objeto de pesquisa bem contemporâneo e relevante para um estudo de caso envolvendo a emergente questão da medição de desempenho em cadeias de suprimentos.

\section{Referências}

ALÁEZ-ALLER, R.; LONGÁS-GARCÍA, J. C. Dynamic supplier management in the automotive industry. International Journal of Operations \& Production Management, v. 30, n. 3, p. 312-335, 2010. http:// dx.doi.org/10.1108/01443571011024647

ALVES FILHO, A. G. et al. Pressupostos da gestão da cadeia de suprimentos: evidências de estudos sobre a indústria automobilística. Gestão \& Produção, v. 11, n. 3, p. 275-288, 2004. http://dx.doi.org/10.1590/ S0104-530X2004000300003

BEAMON, B. M. Supply chain design and analysis: Models and methods. International Journal of Production Economics, v. 55, n. 3, p. 281-294, 1998. http://dx.doi. org/10.1016/S0925-5273(98)00079-6

BEAMON, B. M. Measuring supply chain performance. International Journal of Operations \& Production Management, v. 19, n. 3, p. 275-292, 1999. http:// dx.doi.org/10.1108/01443579910249714

BRANDÃO, H. P.; GUIMARÃES, T. A. Gestão de Competências Gestão do Desempenho: tecnologias distintas ou instrumentos de um mesmo constructo? Revista de Administração de Empresas, v. 41, n. 1, p. 8-15, 2001. http://dx.doi.org/10.1590/ S0034-75902001000100002

CARVALHO, R. Q. et al. Globalização e reestruturação da cadeia produtiva na indústria automotiva: qual é o papel do Mercosul? Convênio IPEA-DPCT/IG/ UNICAMP. FUNCAMP, 2000. 252 p. Relatório Final.

CHIA, A.; GOH, M.; HUM, S. H. Performance measurement in supply chain entities: balanced scorecard perspective. Benchmarking: An International Journal, v. 16, n. 5, p. 605-620, 2009.

COX, J. F.; BLACKSTONE, J. H.; SPENCER, M. S. APICS Dictionary. 8th. ed. Falls Church: American Production and Inventory Control Society, 1995.

CUNHA, V.; ZWICKER, R. Antecedentes do relacionamento e da performance em empresas da cadeia de suprimentos: estruturação e aplicação de modelos de equações estruturais. Revista de Administração de Empresas, v. 49, n. 2, p. 147-161, 2009. http://dx.doi. org/10.1590/S0034-75902009000200003

CROXTON, K. L. et al. The Supply Chain Management Processes. International Journal of Logistic Management, v. 12, n. 2, p. 13-36, 2001. http://dx.doi. org/10.1108/09574090110806271

DAUGHERTY, P. J. Review of logistics and supply chain relationship literature and suggested research agenda. International Journal of Physical Distribution \& Logistics Management, v. 41, n. 1, p. 16-31, 2011. http://dx.doi.org/10.1108/09600031111101402

ECCLES, R. G. Manifesto da mensuração do desempenho. In: HARVARD BUSINESS REVIEW. Medindo o 
Desempenho empresarial. Rio de Janeiro: Editora Campus, 2000.

FABBE-COSTES, N.; JAHRE, M. Supply chain integration and performance: a review of the evidence International Journal of Logistics Management, v. 19, n. 2, p. 130-154, 2008. http://dx.doi.org/10.1108/09574090810895933

FLEURY, A. The changing pattern of operations management in developing countries: the case of Brazil. International Journal of Operations \& Production Management, v. 19, n. 5-6, p. 552-564, 1999. http:// dx.doi.org/10.1108/01443579910260874

GEREFFI, G. International trade and industrial upgrading in the apparel commodity chain. Journal of International Economics, v. 48, n. 1, p. 37-70, 1999. http://dx.doi. org/10.1016/S0022-1996(98)00075-0

GREEN JUNIOR, K. W.; WHITTEN, D.; INMAN, R. A. The impact of logistics performance on organizational performance in a supply chain context. Supply Chain Management: An International Journal, v. 13-14, p. 317-327, 2008.

GULLEDGE, T.; CHAVUSHOLU, T. Enterprise Integration, Inc., Alexandria, Virginia, USA and George Mason University, Fairfax, Virginia, USA, and Automating the construction of supply chain key performance indicators. Industrial Management \& Data Systems, v. 108, n. 6, p. 750-774, 2008. http://dx.doi. org/10.1108/02635570810883996

GUNASEKARAN, A.; PATEL, C.; TIRTIROGLU, E. Performance measures and metrics in a supply chain environment. International. Journal of Operations \& Production Management, v. 21, n. 1-2, p. 71-87, 2001. http://dx.doi.org/10.1108/01443570110358468

HELPER, S. How much has really changed between U.S. automakers and their suppliers? Sloan Management Review, v. 32, n. 4, p. 15-28, 1991.

HILSDORF, W. C.; ROTONDARO, R. G.; PIRES, S. R. I. Integração de processos na cadeia de suprimentos e desempenho do serviço ao cliente: um estudo na indústria calçadista de Franca. Gestão \& Produção, v. 16, n. 2, p. 232-244, 2009. http://dx.doi.org/10.1590/ S0104-530X2009000200007

HOLMBERG, S. A systems perspective on supply chain measurements. International Journal of Physical Distribution \& Logistics Management, v. 30, n. 10 , p. 847-868, 2000. http://dx.doi. org/10.1108/09600030010351246

HRONEC, S. M. Sinais Vitais: Usando Medidas de Desempenho da Qualidade, Tempo, e Custos para traçar a rota do futuro da sua empresa. São Paulo: Makron Books, 1994.

KAYDOS, W. Measuring, managing and maximizing performance. Portland: Productivity Press, 1991.

LAMBERT, D. M.; COOPER, M. C.; PAGH, J. D. Supply Chain management: Implementation Issues and Research Opportunities. International Journal of Logistics Management, v. 9, n. 2, p. 1-19, 1998. http://dx.doi. org/10.1108/09574099810805807

LAMBERT, D.; POHLEN, T. Supply Chain Metrics. The International Journal of Logistics Management, v.12, n. 1, p. 1-19, 2001. http://dx.doi. org/10.1108/09574090110806190
LAMMING, R. C. Beyond partnership - Strategies for innovation and lean supply. London: Prentice-Hall, 1993.

McCORMACK, K.; LADEIRA, M. B.; OLIVEIRA, M. P. V. Supply chain maturity and performance in Brazil. Supply Chain Management: An International Journal, v. 13, n. 4, p. 272-282, 2008. http://dx.doi. org/10.1108/13598540810882161

MOTTA, F. P.; VASCONCELOS, I. F. G. Teoria Geral da Administração. Bookman: Porto Alegre, 2005.

NAURI, M. H. C. As medidas de desempenho como base para a melhoria continua dos processos: 0 caso da Fundação de Amparo à Pesquisa e Extensão Universitária (FAPEU). 1998. Dissertação (Mestrado em Engenharia de Produção)-Universidade de Santa Catarina, Florianópolis, 1998.

NEELY, A. et al. Performance measurement system design: developing and testing a process-based approach. International Journal of Operations \& Production Management, v. 20, n. 10, p. 1119-1145, 2000. http:// dx.doi.org/10.1108/01443570010343708

OLIVEIRA, G. T.; MARTINS, R. A. Efeitos da Adoção do Modelo do Prêmio Nacional da Qualidade na Medição de Desempenho: estudos de caso em empresas ganhadoras do prêmio. Gestão \& Produção, v. 15, p. 167-179, 2008. http://dx.doi.org/10.1590/S0104-530X2008000200004

OU, C. S. et al. A structural model of supply chain management on firm performance. International Journal of Operations \& Production Management, v. 30, n. 5, p. 526-545, 2010. http://dx.doi. org/10.1108/01443571011039614

PAPAKIRIAKOPOULOS, D.; PRAMATARI, K. Collaborative performance measurement in supply chain. Industrial Management \& Data Systems, v. 110, n. 9, p. 1297-1318, 2010. http://dx.doi. org/10.1108/02635571011087400

PIRES, S. R. I.; SACOMANO NETO, M. New Configurations in Supply Chains: The Case of a Condominium in Brazil's Automotive Industry. Supply Chain Management: an International Journal, v. 13, p. 37-48, 2008. http:// dx.doi.org/10.1108/13598540810882215

PIRES, S. R. I. Gestão da Cadeia de Suprimentos: conceitos, estratégias, práticas e casos. São Paulo: Atlas, 2004.

RICHEY JUNIOR, R. G. et al. The moderating role of barriers on the relationship between drivers to supply chain integration and firm performance. International Journal of Physical Distribution \& Logistics Management, v. 39, n. 10, p. 826-840, 2009. http:// dx.doi.org/10.1108/09600030911011432

RITCHIE, B.; BRINDLEY, C. Supply chain risk management and performance A guiding framework for future development. International Journal of Operations \& Production Management, v. 27, n. 3, p. 303-322, 2007. http://dx.doi.org/10.1108/01443570710725563

RODRIGUES, D. M.; SELLITTO, M. A. Análise do desempenho de fornecedores de uma empresa de manufatura apoiada em análise de aglomerados. Produção, v. 19, n. 1, p. 55-69, 2009. http://dx.doi. org/10.1590/S0103-65132009000100005

SLACK, N. Vantagem Competitiva em Manufatura. 3. ed. São Paulo: Atlas, 1993. 
SELLITTO, M. A.; MENDES, L. W. Avaliação comparativa do desempenho de três cadeias de suprimentos em manufatura. Produção, v. 16, n. 3, p. 552-568, 2006. http://dx.doi.org/10.1590/S0103-65132006000300015

SHEPHERD, C.; GUNTER, H. Measuring supply chain performance: current research and future directionsInternational. Journal of Productivity and Performance Management, v. 55, n. 3-4, p. 242-258, 2006. http://dx.doi.org/10.1108/17410400610653219

SONI, G.; KODALI, R. Internal benchmarking assessment of supply chain performance. Benchmarking: An International Journal, v. 17, n. 1, p. 44-76, 2010.

STORPER, M.; HARRISON, B. Flexibility, hierarchy and regional developments: the changing structure of industrial production systems and their forms of governance in the 1990s. Research Policy, v. 20, n. 5, p. 407-422, 1991. http://dx.doi.org/10.1016/0048-7333(91)90066-Y
SUZIGAN, W.; GARCIA, R.; FURTADO, J. Governança de Sistemas de MPMES em clusters Industriais. In: SEMINÁRIO INTERNACIONAL "POLÍTICAS PARA SISTEMAS PRODUTIVOS LOCAIS DE MPMES”, 2002, Rio de Janeiro. Anais... Rio de Janeiro, 2002.

TAN, K. C. et al. Supply chain information and relational alignments: mediators of EDI on firm performance. Distribution \& Logistics Management, v. 40, n. 5, p. 377-394, 2010. http://dx.doi. org/10.1108/09600031011052831

WAGGONER, D. B.; NELLY, A. D.; KENNERLEY, M. $P$. The forces that shape organizational performance measurement systems: An interdisciplinary review. International Journal of Production Economics, v. 60 , n. 61, p. 53-60, 1999. http://dx.doi.org/10.1016/ S0925-5273(98)00201-1 